\title{
Adequacy of Work Environments in Public Dispensaries and Health Centers in Machakos County, Kenya
}

\author{
Patrick Njogu ${ }^{1, *}$, Charles Mburu², Benson Karanja ${ }^{2}$ \\ ${ }^{1}$ Department of Health, Nyeri County, Kenya \\ ${ }^{2}$ Institute of Energy and Environmental Technology, Jomo Kenyatta University of Agriculture and Technology, Juja, Kenya
}

Email address:

njogupatrick@gmail.com (P.Njogu)

${ }^{*}$ Corresponding author

\section{To cite this article:}

Patrick Njogu, Charles Mburu, Benson Karanja. Adequacy of Work Environments in Public Dispensaries and Health Centers in Machakos County, Kenya. Journal of Health and Environmental Research. Vol. 4, No. 4, 2018, pp. 135-139. doi: 10.11648/j.jher.20180404.13

Received: October 19, 2018; Accepted: November 7, 2018; Published: December 3, 2018

\begin{abstract}
The Occupational Safety and Health Act (OSHA) mandates employers to uphold the highest standards of occupational safety and health in their workplaces. However, occupational incidents persist in public health facilities. The researcher sought to assess the adequacy of work environments in public dispensaries and health centers in Machakos County. The study was a cross-sectional survey conducted in February, 2018 involving fourteen (14) dispensaries and seven (7) health centers. Researchers took linear dimensions and angles in the facilities. Assessment involved measuring workrooms, doors, windows, and passageways; computing areas and air volumes; and observing patient examination couches and material storage. The researcher recorded data in checklists then tabulated and analyzed for adequacy. $79 \%$ of the workrooms ceiling heights were less than the required $3 \mathrm{~m} .52 .5 \%$ of the workrooms had less air volumes per worker than the specified $10 \mathrm{~m}^{3}$. $61.5 \%$ of the rooms did not have through ventilation. All the 27 patient examination couches had no height adjusters. $77.8 \%$ of material storage shelves had no equipment to reach heights. $51.3 \%$ of doors were less than $900 \mathrm{~mm}$ wide. $57.1 \%$ of passageways were less than 1.2 meters wide. $61.9 \%$ of the passageways were obstructed. Work environments within the selected facilities were inadequate. OSHA should be reviewed to provide standards for various elements. Directorate of safety and health services should help health facilities to improve adequacy of work environments. Health management should make all aspects of work environments adequate.
\end{abstract}

Keywords: Adequacy, Work Environments, Dispensaries and Health Centers, Machakos County

\section{Introduction}

Occupational safety and health (OSH) is a study domain which focuses on the prevention of work-related injuries and ill-health through the provision of suitable conditions of employment, to attain and maintain the highest level of health of all workers [1]. It embraces several branches of science and is adopted by a range of professionals who uphold the health of workers [2]. Protecting workers is a deliberate ILO mandate to safeguard their safety and health from disregard, and to ensure that occupational illness or injury does not cause loss of employment [3] Health workers were approximately 43 million in the year 2013 and are projected to be about 67.3 million by the year 2030 [4] These employees need protection from a diversity of occupational hazards [5].

Hazardous working conditions contribute to morbidity and mortality among health workers [6]. Ill-health and fatality result in loss of skilled health personnel [7] and cause immense human suffering and financial burden [8] to families, communities, organizations, and governments [3]. The incidence of industrial illnesses and injuries in hospitals of the United States (US) was 68 cases per 1000 regular employees in the year 2011 [7]. In the US, HealthcareAssociated Infections (HAIs) exceeding 1.7 million, and 99,000 related deaths occur annually [9]. HAIs are estimated to account for an average of $10 \%$ of hospital admissions and up to $31 \%$ in countries with constrained resources [10]. 
Healthcare settings post more lost-work-day cases each year, and the probability of employees in healthcare suffering injury is higher than in other sectors [7].

\subsection{Problem Statement}

The Kenya Occupational Safety and Health Act (OSHA) [11] mandates employers to ensure safe and healthy work environments and maintain the highest OSH standards in their workplaces. However, work-related incidents such as needle-stick injuries and toxic gas exposures persist in Kenyan health sector [12]. The risk of occupational exposures among the healthcare workers is high [13]. To best of available knowledge, there are no published studies to elucidate the adequacy of work environments in the public health facilities. The researcher aimed to assess occupational safety and health elements in the health facilities and publish findings.

\subsection{Scope of the Study}

The researcher assessed adequacy of work environments in the public dispensaries and health centers in Machakos County only.

\section{Methods}

The study was a cross-sectional descriptive survey conducted in February, 2018 involving fourteen (14) dispensaries and seven (7) health centers. Stratified and simple random sampling methods were applied in determining the health facilities to include in the study. A measuring tape took linear measurements and a protractor measured angles. The researcher measured workrooms, doors, windows, and passageways then computed areas and air volumes. As required in the OSHA, the maximum ceiling height of $4.5 \mathrm{~m}$ applied when computing the air volumes of the workrooms. The total volume of any fixed cabinet(s) in a workroom was subtracted from the computed room volume. The researcher used the number of seats which were found arranged for normal working situation to determine the number of workers in each workroom. The formula: [(Floor area $x$ Ceiling Height) - Volume of Fixed Cabinets] / Number of workers was used to determine air volume per worker. The researcher also assessed patient examination couches and commodity storage pshelves for adequacy. Data collected was recorded in pchecklists, then tabulated and analyzed for compliance.

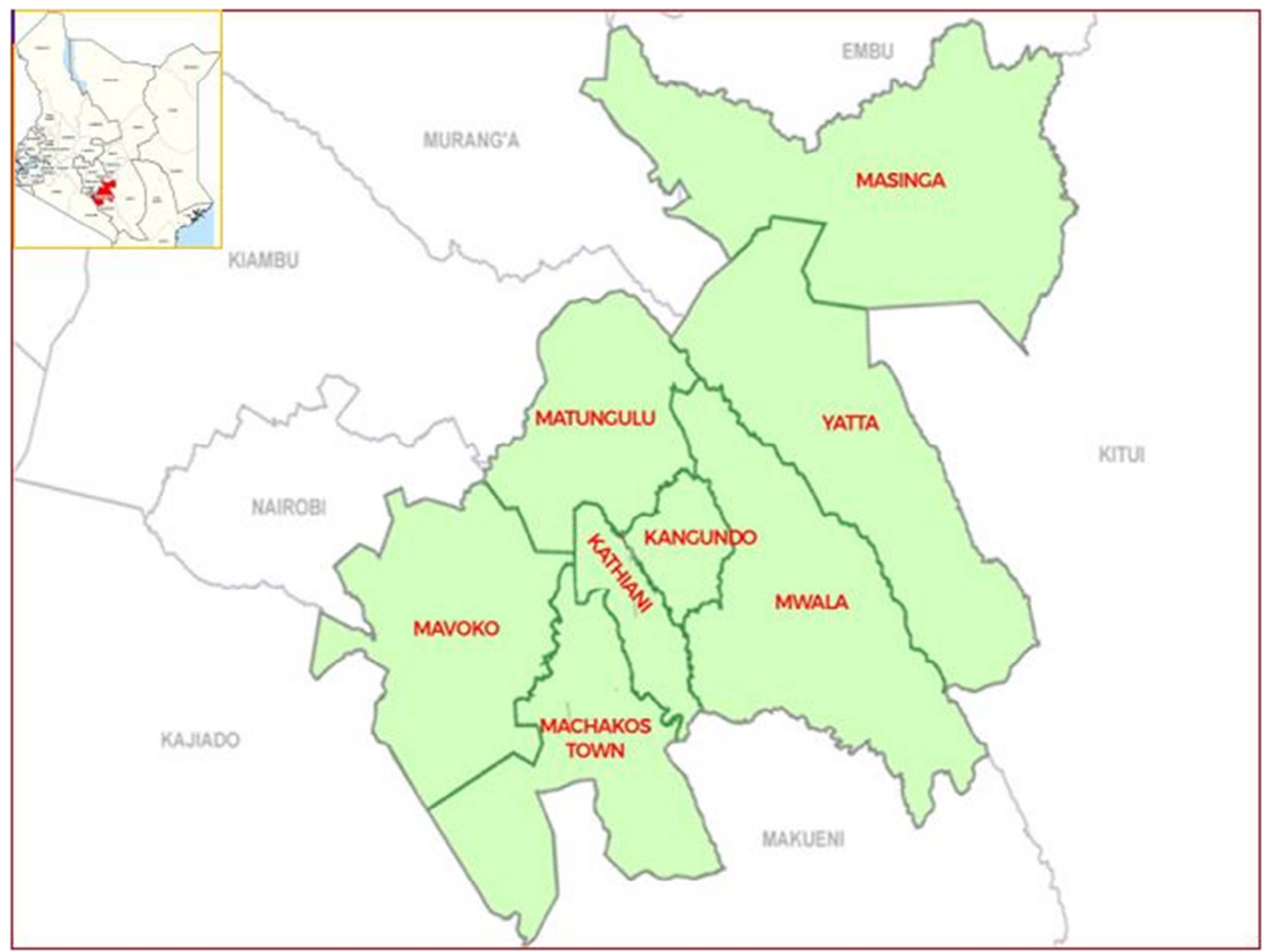

Figure 1. Map of Machakos County. 


\section{Results and Discussions}

Table 1. Results of Work Environment Assessment.

\begin{tabular}{lll}
\hline Environmental Element & Number Assessed & Percentage Compliant \\
\hline 1. The facility has a building Plan & 21 & $23.8 \%$ \\
2. The Building Plan is approved by DOSHS & 5 & $0 \%$ \\
3. Height of Workroom $\geq 3 \mathrm{~m}$ & 80 & $21 \%$ \\
4. Air volume of workroom $\geq 10 \mathrm{~m}^{3}$ per worker & 80 & $47.5 \%$ \\
5. Width of full-open door $\geq 900 \mathrm{~mm}$ & 80 & $48.8 \%$ \\
6. Door shutters swing outward & 80 & $40.0 \%$ \\
7. Door not lockable from inside & 80 & $42.5 \%$ \\
8. Surface Area of window $\geq 10 \%$ of the room floor area & 80 & $81.3 \%$ \\
9. Opening Surface Area of window $\geq 6.25 \%$ of the room floor area & 80 & $84.4 \%$ \\
10. Window shutter full opening angle $=180^{\circ}$ & 96 & $35.4 \%$ \\
1. Through Natural Ventilation in the Workroom & 80 & $38.5 \%$ \\
12. Width of Passageway $\geq 1.2 \mathrm{~m}$ & 21 & $42.9 \%$ \\
13. Passageway not obstructed & 21 & $38.1 \%$ \\
14. Emergency Exit door provided & 21 & $57.1 \%$ \\
15. Width of Emergency Exit door $\geq 900 \mathrm{~mm}$ & 12 & $30.0 \%$ \\
16. Marked Fire Assembly point & 21 & $81.0 \%$ \\
17. Materials storage shelves stable & 18 & $72.2 \%$ \\
18. Materials storage shelves not obstructing windows & 18 & $44.4 \%$ \\
19. Materials storage shelves with equipment to reach heights & 18 & $22.2 \%$ \\
20. Patient Examination Couch With adjustable height & 27 & $0 \%$ \\
Aggregate mean & & $42.5 \%$ \\
\hline
\end{tabular}

\subsection{Approval of Buildings}

$23.8 \%$ of all the twenty-one (21) health facilities assessed maintained building plans of the existing building(s). None of the plans was approved by the Directorate of Occupational Safety and Health Services (DOSHS). OSHA requires all building or alteration plans for all workplaces to be approved by the directorate. These results showed that facilities were not compliant with law.

\subsection{Heights of Workrooms}

$79 \%$ of the workrooms had ceiling heights of less than the minimum three meters (3m) specified by OSHA. Based on these results, the working environments in the workrooms were not permissible.

\subsection{Air, Ventilation and Lighting}

$52.5 \%$ of the workrooms had less air volumes per worker than the $10 \mathrm{~m}^{3}$ required. $61.5 \%$ of the workrooms did not have through ventilation. OSHA requires each workroom to have a minimum air volume of ten cubic meters $\left(10 \mathrm{~m}^{3}\right)$ per worker, and effective adequate natural ventilation provided in each workroom. While the Act does not provide standards for the requirement, the National Planning and Building Authority regulations (NPBA), 2009 [14] specifies that workrooms should have through ventilation. $15.6 \%$ of the window opening areas were less than $6.25 \%$ of the room floor area required by NPBA (2009) as the least. The results indicated that natural ventilation was not acceptable.

$55.6 \%$ of commodity storage shelves were obstructing windows, contrary to the provisions of OSHA. The NPBA (2009) requires the total window surface area in a workroom to be at least $10 \%$ of the room floor area but $18.7 \%$ of the workrooms had less. The results showed that these rooms had insufficient natural lighting.

\subsection{Risks from Windows}

$64.6 \%$ of the windows fully opened to less than $180^{\circ}$, making them project to passages when open. These projecting windows had the risk of being hit by people passing by them. OSHA requires a window not to be a source of risk to people. Although the Act does not explain further on this requirement, the Health and Safety Authority regulations (2007) [15] stipulate that a window should not project to areas where people pass. This implies that it should be constructed such that the full opening angle is $180^{\circ}$ so that it lies flat on the wall behind when open. Based on the results the researcher deduced that the windows provided deplorable work environments.

\subsection{Manual Handling}

All the twenty-seven (27) patient examination couches had no mechanism to adjust heights. ILO (2012) [16] requires work surfaces to be such that they allow all workers use them at or below their elbow heights. The examination couches exposed health workers to manual lifting and lowing of patients. $27.8 \%$ of material storage shelves were not stable therefore, contravening OSHA which provides that storage of materials should be such that they cannot collapse. These unstable shelves created a risk of collapsing on workers. $77.8 \%$ of the shelves were not provided with equipment to reach materials in heights. According to ILO (2012), materials to be lifted must be kept at shoulder level and workers should not be exposed to lifting, carrying or reaching materials above shoulder level. These results demonstrated that health workers exposed to intolerable patient and material handling in the work environments. 


\subsection{Workplace Access and Exit}

$60 \%$ of the doors were swinging inwardly while $57.5 \%$ had widths of less than $900 \mathrm{~mm}$. $57.5 \%$ of the doors were locked from inside. OSHA requires workrooms to have adequate access and exits. The Act further provides that door shutters should swing outward and not to be lockable from inside. While the Act fails to specify standard sizes of doors, NPBA (2009) provides that each workroom door should have a minimum opening width of $900 \mathrm{~mm}$. Based on the results the doors did not provide sufficient access and exit to the workrooms.

While none of the workrooms had the stipulated individual emergency exit doors [11], $57.1 \%$ of the health facilities had emergency exits from their passageways. $67 \%$ of the exits were less than $900 \mathrm{~mm}$ wide contrary to OSHA. $57.1 \%$ of the passageways were less than $1.2 \mathrm{~m}$ wide and $61.9 \%$ of them were obstructed. OSHA stipulates that passageways must be of adequate width and unobstructed. While the Act does not provide standard widths of passageways, NPBA (2009) specifies the minimum width of passages in buildings where people work to be at least $1.2 \mathrm{~m}$. The OSHA provides that passageways should not be obstructed. The results showed that emergency exits in the health facility workplaces were not compliant with the existing law.

\section{Conclusions}

Natural ventilation and lighting in the public dispensaries and health centers were not tolerable. $79 \%$ of the workrooms had less ceiling heights than the minimum acceptable limit of three meters $(3 \mathrm{~m}) .52 .5 \%$ of the workrooms failed to attain the minimum air volume of $10 \mathrm{~m}^{3}$ per worker. $61.5 \%$ of the rooms did not have through ventilation; and $18.7 \%$ of workrooms did not have the minimum permissible natural lighting.

There was high risk of injury within the health facility work environments. $64.6 \%$ of the windows projected to passages, therefore, posing risk of being hit by people passing. All the patient examination couches had no mechanism to adjust heights. $27.8 \%$ of material storage shelves were unstable with risk of collapsing and causing injury to workers. $77.8 \%$ of the storage shelves had no equipment to reach materials in heights.

Access and exit in the workrooms were not permissible. $57.5 \%$ of the workroom doors had less opening widths than the specified minimum of $900 \mathrm{~mm}$. $60 \%$ of the doors opened inwardly while $57.5 \%$ of the doors were locked from inside.

Emergency escape from the workrooms was not adequate. All the workrooms did not have individual emergency exit doors. $57.1 \%$ of passageways were narrower than the specified minimum width of $1.2 \mathrm{~m}$. $61.9 \%$ of the passageways were obstructed. $70 \%$ of the emergency exits provided in the passages were not marked.

The National authority responsible for occupational safety and health services, DOSHS, was not keen on the public health facilities. All the twenty-one (21) health facilities assessed did not have their building plans approved by the directorate. This indicated the directorate was absent in the health facilities.

The Kenya occupational safety and health Act is the main legislation that guides the management of occupational safety and health in Kenya. The Act does not provide standards for various occupational safety and health components of work environments. It requires effective and adequate natural ventilation without specifying standards. It provides that a window should not to be a source of risk to people, but fails to explain further. The Act stipulates that adequate access and exit must be provided in workrooms but does not specify the minimum opening width of doors. According to the Act, passageways in work areas must be of adequate width. It does not, however, provide the minimum acceptable width of the passages.

\section{Recommendations}

The health management should take necessary measures to ensure the various occupational safety and health elements are adequate. The ceiling heights of the workrooms should be at least $3 \mathrm{~m}$. Windows should be placed opposite windows or doors and must have total surface areas of at least $10 \%$ of the respective floor areas with a minimum of $6.25 \%$ of the floor area being open able. The windows must be installed such that they lie on the wall behind when fully open.

The patient examination couches should have height adjusters and the material storage shelves be made stable and provided with safe equipment to reach materials in heights. Access doors and emergency exits of a minimum of $900 \mathrm{~mm}$ wide must be provided to each workroom and made to open outwardly. Passageways must have a minimum width of $1.2 \mathrm{~m}$ and maintained without obstruction.

The Directorate of occupational safety and health services should consider health facilities like any other workplaces and help them improve their work environments. It should ensure that the prevailing conditions in the health facilities are corrected, and new health facility buildings consider all elements occupational safety and health at the design stage. The Kenya Occupational Safety and Health Act, 2007 should be revised to include standards for the various elements of the work environments. Further research may be conducted to examine other elements of occupational safety and health in the health facilities.

\section{Acknowledgements}

Sincere appreciation goes to the Machakos County Commissioner, County Director of Health Services, SubCounty medical officers, and the in-charges of health facilities visited for allowing me to conduct the research in the study area. I am greatly indebted to all those who participated in this research for their time and assistance. This research could not have been a success without the assistance of these institutions and persons. 


\section{Competing Interests}

There was no competing interest

\section{Authors' Contributions}

1. Originated the research theme; research design; data collection, analysis and interpretation; and dissemination of results

2. Provided intellectual stimulation and technical guidance

\section{References}

[1] International Labor Organization (2011). Occupational Safety and Health Management System: A Tool for Continual Improvements: World Day for Safety and Health at Work: International Labor Office (ILO): Geneva.

[2] Takele Tadesse \& Mengesha Admassu (2006). Occupational Health and Safety: Lecture Notes for Environmental and Occupational Health Students. Ethiopia: University of Gondar.

[3] International Labor Organization (2010). Safety and Health at Work: International Labor Office (ILO): Geneva.

[4] World Health Organization (2016). Health Workforce Requirements for Universal Health Coverage and the Sustainable Development Goals: Human Resources for Health Observer, 17. Geneva: WHO.

[5] World Health Organization (2010). Health Worker Occupational Health. In: WHO (Ed) Occupational Health Health workers, Volume 2012. Geneva: WHO.

[6] Ndejjo, R., Musinguzi, G., Yu, X., Buregyeya, E., Musoke, D., Wang, J. S. ... \& Ssempebwa, J. (2015). Occupational Health Hazards among Healthcare Workers in Kampala, Uganda. Journal of Environmental and Public Health, 2015, 913741-
913741.

[7] Occupational Safety and Health Administration (2013). Safety and Health Management Systems: Facts about Hospital Worker Safety- New York: U.S. Department of Labor.

[8] European Union (2011). Occupational Health and Safety Risks in the Healthcare Sector: Guide to Prevention and Good Practice. Luxembourg: Publications Office of the European Union.

[9] Klevens, R. M., Edwards, J. R., Richards Jr, C. L., Horan, T. C., Gaynes, R. P., Pollock, D. A., \& Cardo, D. M. (2007). Estimating Health Care-Associated Infections and Deaths in US Hospitals, 2002. Public health reports, 122(2), 160-166.

[10] Ministry of Health (2010). National Infection Prevention and Control Guidelines for Health Care Services in Kenya: Nairobi: $\mathrm{MOH}$.

[11] Government of Kenya (2007). Occupational Safety and Health Act. Kenya Law Reform Commission, Nairobi: Government Printer.

[12] Kenya Ministries of Health and IntraHealth International (2013). Report of the Occupational Safety and Health Risk Assessment. Nairobi: $\mathrm{MsOH}$.

[13] Ministry of Health (2016). Occupational Exposure to Blood and Body Fluids and HIV Post-exposure Prophylaxis in Health Care Facilities in Kenya 2011 - 2014. Nairobi: MOH.

[14] National Planning and Building Authority (NPBA), (2009). Planning and building Regulations, Volume 2 \& 4.

[15] Health and Safety Authority (2007). The Guide to Safety, health and Welfare at Work(General Application) Regulations 2007. Dublin: Health and Safety Authority, Retrieved from: http://www.hsa.ie/eng/.

[16] International Labor Organization (2012). Your safety and health at work: Basic ergonomics principles, Geneva: International Labor Office. 